\title{
The road towards industry 4.0: a comparative study of the state-of-the-art in the Italian manufacturing industry
}

\author{
Ting Zheng, Marco Ardolino, Andrea Bacchetti and Marco Perona \\ Rise Laboratory, Department of Mechanical and Industrial Engineering, \\ Universita degli Studi di Brescia, Brescia, Italy
}

\begin{abstract}
Purpose - This paper has two objectives: first, to investigate the state-of-the-art of Industry 4.0 (I4.0) adoption in Italian manufacturing firms and, second, to understand variations in technologies implemented and business functions involved, benefits perceived, and obstacles encountered in I4.0 implementation over a three-year period.

Design/methodology/approach - The approach adopted in this research is descriptive, nesting longitudinal features. The paper presents a descriptive survey of 102 Italian manufacturing companies. The authors also evaluated non-response biases. The longitudinal approach was achieved by comparing the responses of the 40 sub-samples in common with a second similar survey launched three years prior, which aimed to identify patterns of evolution in the adoption of the I4.0 paradigm.

Findings - Survey findings demonstrate that Italian manufacturing companies still have limited awareness of I4.0 technologies, and the adoption of I4.0 technologies differs per technology. Company size and information system coverage level are the two factors that impact the company's technology adoption level. The comparative study shows that knowledge and adoption increase in a three-year interval with an unbalanced involvement of business functions regarding the I4.0 transformation. Indeed, companies are still seeking I4.0 solutions to reduce costs and lead times primarily, and the benefits perceived by companies are shown to be related to the number of I4.0 technologies in use. Finally, when companies put the I4.0 technologies into practice, competence is constantly considered the most significant barrier.

Research limitations/implications - This paper aims at conducting a thorough investigation into the development of I4.0 adoption in manufacturing companies. The main limitation of this study concerns the limited number of subjects involved in the longitudinal study (40) and the focus on a limited geographical area (Italy). In addition, more I4.0 technologies could also be incorporated into the survey protocol to gain further insight into I4.0 development.

Originality/value - The authors provide one of the first attempts to assess the variations of I4.0 implementation concerning technology adoption, business function involvement, and the alteration of benefits and obstacles. Several studies presented in the literature highlight the lack of longitudinal studies investigating the development of the I4.0 paradigm in a specific manufacturing context: this paper is the attempt at filling this gap.
\end{abstract}

Keywords Industry 4.0, Digitalization, Technology, Manufacturing technology, Survey

Paper type Research paper

\section{Introduction}

In recent years, manufacturing firms have been involved in an increasingly competitive business environment, characterised by trends of customisation, higher requirements on resource efficiency, shortened delivery time and requests for premium quality (Brettel et al.,

(C) Ting Zheng, Marco Ardolino, Andrea Bacchetti and Marco Perona. Published by Emerald Publishing Limited. This article is published under the Creative Commons Attribution (CC BY 4.0) licence. Anyone may reproduce, distribute, translate and create derivative works of this article (for both commercial and non-commercial purposes), subject to full attribution to the original publication and authors. The full terms of this licence may be seen at http://creativecommons.org/licences/by/4.0/legalcode
The road towards industry 4.0

Received 27 January 2021 Revised 11 August 2021 Accepted 12 November 2021 
BIJ

30,1

308
2014; Lasi et al., 2014). Moreover, complexity in the manufacturing industry is increasing (Galati and Bigliardi, 2019; Hofmann and Rüsch, 2017), calling for effective integration and visibility across the entire supply chain (Tiwari, 2020). Simultaneously, technological advances have shed light on new business opportunities (Brad et al., 2018; Hanelt et al., 2021).

To adapt to the dynamic, changing environment, manufacturers seek digital approaches to save costs and achieve faster time-to-market through updating technological solutions, a process known as Industry 4.0 (I4.0) transformation (Oesterreich and Teuteberg, 2016; Ortt et al., 2020). I4.0 represents the fourth industrial revolution and includes horizontal integration of information flows among all the stakeholders involved in the supply chain and vertical integration within the industry environment. The past three industrial revolutions have been driven my mechanisation, electricity and information technology (IT), respectively (Veza et al., 2015), while digital technologies represent the common feature of I4.0 initiatives.

For I4.0, the underlying pillar is adopting the internet of things (IoT) integrated into industrial value creation (Ivanov et al., 2016). According to Schumacher et al. (2016), the IoT serves as the backbone to integrate physical objects, human actors, intelligent machines, product lines and processes across organisational boundaries. In addition, other digital technologies also emerge as enablers of the I4.0 paradigm, such as Big Data and Analytics (BDA), Artificial Intelligence (AI), Augmented and Virtual Reality (AR and VR), Collaborative Robotics and Additive Manufacturing (AM), whose applications cover a wide range of manufacturing processes and could realise more autonomous and efficient scenarios.

Current literature has investigated the I4.0 phenomenon from different perspectives by adopting various approaches, such as studying what I4.0 is, how to implement I4.0, and the company's maturity level of I4.0 (Ortt et al., 2020). From the perspective of using extensive sample data to evaluate the I4.0 impact on manufacturing companies, studies attempting to investigate the I4.0 in different regions or countries are presented in the literature. For example, Tortorella and Fettermann (2018) explore the implementation state of I4.0 and lean production (LP) practices and their association with Brazilian manufacturing companies. They also examined how I4.0 technologies moderate LP practices to impact operational performance. In particular, the increase in studies focusing on single countries is motivated by the fact that the advent of I4.0 is representative of a national strategy for industrial renovation. Therefore, the literature should invest resources in investigating the relationships between I4.0 adoption effectiveness in manufacturing companies and specific contextual factors such as national industrial resources (Galati and Bigliardi, 2019). Moreover, it is highly valuable to scrutinise the means of realisation of Industry 4.0 across geographical regions (Wagire et al., 2019).

The implementation of I4.0 also differs per sector and type of company (Ortt et al., 2020). Some specific industrial contexts are characterised by features that highlight peculiarities in the adoption of digital technologies. For example, an important benchmark is company size. For example, Rossini et al. (2019) surveyed the interrelation between I4.0 and lean production among European manufacturers. Also, Masood and Sonntag (2020) test the relationship between company size, manufacturing complexity and attitudes towards I4.0 with the benefits and challenges of adopting I4.0 technologies for small and medium enterprises (SMEs) in the UK.

Conclusively, the study of geographical areas characterised by a majority of SMEs helps to understand the maturity level of SMEs in adopting Industry 4.0 and the real advantages that can be achieved (Galati and Bigliardi, 2019; Schneider, 2018). The various driving forces and inhibiting factors affecting SMEs are still under investigation (Horváth and Szabó, 2019).

At the same time, there is great potential for research to provide evidence from the implementation of specific Industry 4.0 technologies through an inductive approach (Schneider, 2018). In this respect, the literature highlights the lack of longitudinal studies to analyse the technology adoption processes in organisations (Schneider, 2018). Cimini et al. 
(2020) and Mihardjo et al. (2019) stress the scarcity of longitudinal research concerning the impact of Industry 4.0 implementation on medium- and long-term performance. Similarly, the benefits and barriers of adopting the paradigm are in constant flux as the evolution of digital technologies is in full swing, as is their application (Tiwari, 2020).

This paper thus tries to fill these gaps, and it is aimed at achieving two main objectives. First is the investigation on the I4.0 adoption in the Italian manufacturing context, while second is the assessment of the progress in implementing I4.0 in the Italian manufacturing industry sector.

Therefore, the two main research questions for this study are as follows:

$R Q 1$. What is the state-of-the-art of Industry 4.0 adoption in Italian manufacturing companies?

RQ2. What are the main I4.0 implementation variations concerning technologies implemented, business functions involved, perceived benefits and obstacles encountered?

To achieve the abovementioned objectives, the state-of-the-art I4.0 adoption was investigated through a survey carried out on a sample of 102 Italian manufacturing companies. Moreover, changes in the adoption of the I4.0 technologies were evaluated and analysed by comparing the results of the abovementioned survey with those of a previous one carried out three years prior by comparing the common sample of 40 respondents. This research refers to the results obtained from two similar empirical surveys carried out at two times: the first in 2017 , and the second in 2020.

Selecting Italian manufacturing companies as the research target derives from the fact that Italy is the second most important European Union (EU) country concerning its sold production value (EC, 2020). Moreover, among various European countries, Italy has also been the subject of some specific studies concerning adopting I4.0 (Bravi and Murmura, 2021; Cimini et al., 2020; Zheng et al., 2019).

The rest of the paper is structured as follows: Section 2 presents the theoretical background of I4.0 enabling technologies, their applications, and their benefits and obstacles. Section 3 describes the empirical setting and survey design. Section 4 shows the survey results, followed by a discussion of the theoretical and managerial implications in Section 5. Finally, the conclusion is drawn in Section 6, and implications and limitations are summarised in Section 7.

\section{Theoretical background}

\subsection{Industry 4.0 enabling technologies and their impacts}

The Industry 4.0 (I4.0) concept was introduced in 2011 in Germany based on the assumption that cyber-physical systems (CPS) can be the enablers of a paradigm shift in the industrial sector (Lu, 2017). Industry 4.0 deals in fact with the digitalisation of the value chain and brings a technology-based opportunity to advance the value generation process of manufacturing companies (Oesterreich and Teuteberg, 2016). Therefore, Industry 4.0 focuses on digital technologies to make procedures and processes more agile, even in turbulent environments (Belinski et al., 2020).

The spread of awareness on I4.0 has had a significant impact on both scholars and practitioners. However, the Industry 4.0 definition is not conclusive because most of the enabling technologies are still emerging and have not already achieved an adequate maturity level (Ojra, 2018). Scholars have suggested different definitions often after reviewing and systematising the extant literature (Majumdar et al., 2021). A common factor characterising I4.0 definitions is the techno-centric perspective, since improvements brought by digital technologies are the enablers of this specific industrial revolution. Nosalska et al. (2020)
The road towards industry 4.0 
BIJ

30,1

310

defined I4.0 as driven by customer needs and mass customisation requirements and enabled by innovative technologies, connectivity, and IT integration. The implementation of CPS, IoT and other enabling technologies, such as Big Data and Analytics (BDA) (Xu and Duan, 2019), Augmented and Virtual Reality (AR and VR) (Damiani et al., 2018), Artificial Intelligence (AI) (Lee et al., 2018), Collaborative Robotics (Malik et al., 2020) and Additive Manufacturing (Dilberoglu et al., 2017) contribute to the creation of integrated systems called the physical and the so-called smart factory (Nosalska et al., 2020; Ortt et al., 2020). The literature aimed at investigating the enabling technologies of the I4.0 paradigm is very disparate, and researchers have contributed by providing different taxonomies and frameworks in this respect (Frank et al., 2019; Zheng et al., 2021).

The adoption of digital technologies in the manufacturing context has multiple applications that can affect each of the processes in the value chain (Zheng et al., 2021). Indeed, the use of IIoT and BDA covers a wide range of business processes in the manufacturing context, from product development to end-of-life (Bag et al., 2018; Bressanelli et al., 2018). Furthermore, the deployment of AR and VR can also support the product development process, as it provides a concrete vision of the product assessment. VR can act as a visualisation platform for aligning physical production lines with the virtual world (Turner et al., 2016), while work instructions enabled by AR help reduce the cognitive load and enable better operators' performance (Blanco-Novoa et al., 2018). Besides, AI is also effective in automated resource allocation of shop floor production and supply chain integration (Cohen et al., 2019; Srai and Lorentz, 2019). The implementation of robotics and $\mathrm{AM}$ are associated with different processes. Collaborative robotics is more adopted in production-related processes, which can improve safety for workers by reducing the risk of injuries, and it usually is helpful in complex task operations (Benotsmane et al., 2019). AM is more related to product-related processes, with the frequent investigation of rapid prototyping and customised product development (Ashour Pour et al., 2019). Indeed, the integrated adoption of enabling technologies could benefit manufacturing companies, such as cost reduction, quality improvement, time reduction and flexibility improvement (Kiel et al., 2017; Kusiak, 2018). Digital technologies are also crucial for manufacturing companies to provide advanced services to their customers, such as predictive maintenance and remote control of production (Ardolino et al., 2018). In this respect, the evolution towards a serviceoriented business model is effectively enabled by digital technologies (Eloranta et al., 2021).

In this paper, the authors consider a list of 6 technologies, resulting from a critical revision of the ones mentioned in reputable research in the literature and the Italian Industry 4.0 national initiative (Ghobakhloo, 2018; Governo Italiano-Ministero dello Sviluppo Economico, 2016; Oztemel and Gursev, 2020; Zheng et al., 2019), namely Industrial Internet of Things (IIoT), BDA, AI, AR and VR, Collaborative Robotics and, finally, AM. The investigated technologies in the survey launched in 2020 align with the survey conducted by authors in 2017 (Zheng et al., 2019); the exception is for AI, a newly added technology in 2020 replacing cloud computing from the 2017 survey.

\subsection{Benefits and obstacles of industry 4.0}

Implementing I4.0 in manufacturing companies might bring significant strategic benefits, leading to improvements in economic and financial performance (Cassetta et al., 2020). The effective implementation and adoption of digital technologies can better meet individual customer requirements and increase added value through new products and services (Kagermann et al., 2013). Indeed, the literature sheds light on the potentialities of business digitalisation to innovate traditional business models for manufacturing companies (Bravi and Murmura, 2021; Rejikumar et al., 2019). Moreover, products, machines and humans can be connected, creating a smart network and effectively integrating all the information in the supply chain (Kamble et al., 2018). Similarly, the decision-making process is made more 
effective by better processing and transforming data into valuable information for optimising decisions (Bienhaus and Haddud, 2018). Indeed, according to Bienhaus and Haddud (2018), digitalisation can better support daily administration and business tasks and help in complex decision-making processes.

To better cope with increasingly complex contexts, digital technologies also allow for improved flexibility and agility to absorb any external shocks that may impact demand (Rejikumar et al., 2019).

Other benefits found in the literature are cost reduction and quality improvement (Moeuf et al., 2018). Researchers and practitioners have accepted the industrial concept of Industry 4.0 as a revolutionary shift that could enable factories to achieve higher product variety with decreased downtimes, energy consumption and improved quality (García-Magro and Soriano-Pinar, 2019; Oztemel and Gursev, 2020). Based on connectivity and computing power, manufactured products could be autonomous products and integrate self-reliant or self-governing ability. According to Ardito et al. (2019), Industry 4.0 has positive reflexes in the deployment of information technology (IT).

However, not all companies have an adequate information technology maturity level to embrace Industry 4.0, which might represent a significant barrier (Müller et al., 2018; Ustundag and Cevikcan, 2018). Indeed, the literature also provides many valuable contributions concerning the barriers and obstacles that inhibit the implementation of I4.0. Schneider (2018) has identified six clusters of managerial challenges for adopting Industry 4.0, ranging from strategic business aspects to those more related to human factors and change management. The top management must appraise the opportunity of value creation, capture and delivery through the adoption of Industry 4.0 and should also champion change management (Devi et al., 2021). Kagermann et al. (2013) investigated the main barriers concerning adopting Industry 4.0, focusing on process and work organisation, technology availability and cybersecurity issues, while Nguyen Ngoc et al. (2021) put human resources at the centre of the digitalisation process. The utilisation of digital technologies calls for a new skilled workforce that goes beyond traditional work profiles (Nimawat and Gidwani, 2021). Another aspect that may inhibit the spread of the I4.0 paradigm is the different maturity levels of the enabling technologies (Gracel and Lebkowski, 2019). As far as specific technologies are concerned, a significant challenge is the effective integration of these technologies and the IT systems used (Carvalho et al., 2018). Last but not least, implementation costs can be an insurmountable barrier, especially for manufacturing companies that do not have sufficient financial capacity to support investment (Raj et al., 2020).

\section{Research design and methodology}

The objectives of this research are two-fold. First is the evaluation of the state-of-the-art of I4.0 adoption in the Italian manufacturing context. Second, the assessment of the evolution in adopting I4.0 in the Italian manufacturing industry sector, focusing on three specific features: (1) technologies adopted; (2) business functions involved; and (3) benefits achieved and obstacles faced. The approach adopted in this study is descriptive, nesting longitudinal features.

The first objective is achieved by analysing the survey results carried out in 2020, while the second objective is achieved based on the comparison of the responses of the sub-sample in common of the two surveys. The research design is summarised in Figure 1.

\subsection{Survey design}

The study is based on a descriptive survey launched in 2017 whose results were previously discussed in Zheng et al. (2019). Therefore, we have conducted a similar study that uses the

The road towards industry 4.0 
BIJ
30,1

\section{2}

Figure 1.

Research design

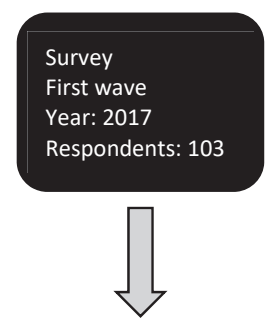

Zheng et al. 2019

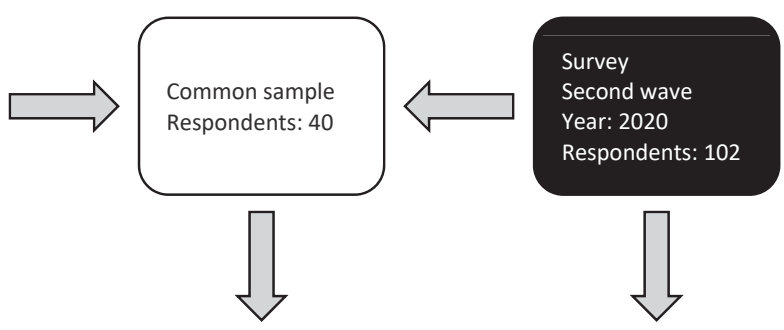

RQ2: What is the main Industry 4.0 implementation variations regarding technologies implemented, business functions impacted, perceived benefits and obstacles encountered?
RQ1: What is the state-of-ofthe-art of Industry 4.0 adoption in the Italian manufacturing companies?

same methodology to measure the phenomenon in 2020. Indeed, a two-wave fixed panel design has been adopted with an interval of three years, grounded on a longitudinal study. Longitudinal studies find their main application in medicine or social sciences to analyse, for example, the evolution of a given pathology or sociological phenomenon within a specific sample. However, this mode of investigation has been used in other studies focusing on analysing the evolution in the manufacturing context of a given phenomenon (Jonsson and Mattsson, 2006; Sohal and Terziovski, 2000).

The process carried out to manage both surveys was the same. We first selected the AIDA (Italian company information and business intelligence) database as a primary information source for sampling. We then considered the mailing list available in the authors' research group. A total of 960 companies were identified, suitable for further contact since the email, telephone and data privacy issues were all conforming to specifications. The initial sample was constructed to reflect the characteristics of the entire population of Italian fabric manufacturers in terms of both size and industry sector.

Among the typical four survey modes - face-to-face, telephone interview, self-completion on paper and web survey - we relied on the web survey, which is much more cost-effective considering the economic and time feasibility (Couper, 2000). Moreover, web surveys do not allow responses to be manually transferred into a database, avoiding interviewer biases (Dillman et al., 2014). We adopted "LimeSurvey" as a web survey tool, which offers an open platform for designing, launching and collecting online surveys. This tool includes (1) mail recording and tracking, which was used to trace the response statuses and (2) a questionnaire, which is the primary tool for collecting compilations answered and archived by the reference person in the company.

For each wave, the data collection period was settled in the first six months of 2017 and 2020. During these months, reminder mailings were sent every two weeks, and follow-up telephone calls were executed to remind respondents of the compilation.

The questionnaire was composed of four sections. The first section was mainly composed of basic information about the company and the respondent. A series of questions concerning the company's existing information system coverage level was asked in the second section. In the third section, the questions referred to organisational competencies. The fourth section was dedicated to the knowledge and adoption of I4.0 enabling technologies.

\subsection{Pilot testing}

The survey process preceded pilot testing to test and improve survey design and questionwording (Forza, 2002). In the first phase, the questionnaire was sent to three colleagues not 
involved in the research project to evaluate the questionnaire's accomplishment with the study objectives (Dillman et al., 2014).

Subsequently, the survey was sent to a pre-test sample characterised by managers working for three manufacturing companies whose characteristics and information about I4.0 adoption were well known by the authors. The pilot test helped the authors evaluate potential improvement areas in the questionnaire based on the answers concerning what was expected.

\subsection{Sample description and data collection}

The description of the sample will be shown from two perspectives. First, the overall sampling in 2020 is depicted, and then the characterisation of the common subsample in 2017 and 2020 is explained. As shown in Table 1, an abundant heterogeneous classification has been achieved with a total sample of 102 companies in 2020, where SMEs represent around $54 \%$ of the sample, $29.4 \%$ are large companies and $16.7 \%$ are huge ones. Moreover, different manufacturing sectors have been targeted. Indeed, the first four sectors of the sample composition account for around $75.7 \%$ of the total sample. More concretely, manufacture of machinery equipment ranks in first place $(43.7 \%)$. From second to fourth place is manufacture of fabricated metal products, manufacture of basic metals and manufacture of motor vehicles, trailers and semi-trailers. Furthermore, regarding the respondent's role, directors such as $\mathrm{CIO}, \mathrm{CTO}, \mathrm{R} \& \mathrm{D}$ director, and production and operations managers account for $75.5 \%$, while top management contributes $17.6 \%$ of the respondent group. Then managers and associates constitute the other $6.9 \%$ of the total sample.

Table 2 describes the company's characteristics that participated in the survey in both waves, separately in 2017 and 2020 ; the number of this sample reached a total of 40 . SMEs still stand for more than $50 \%$ of the sample, followed by large and very large companies from a company size perspective. Regarding the manufacturing sector, companies belonging to manufacture of machinery equipment, manufacture of fabricated metal products, and manufacture of basic metals occupy a total of $70.0 \%$. In addition, $38 \%$ of respondents are

\begin{tabular}{|c|c|c|c|c|}
\hline & No. & $\begin{array}{l}\text { ercentage } \\
(\%)\end{array}$ & Classification criterion & \\
\hline \multicolumn{5}{|l|}{ Company size } \\
\hline SME & 55 & 53.9 & Turnover $\leq € 50 \mathrm{~m}$ & \\
\hline Large & 30 & 29.4 & $\begin{array}{l}€ 50 \mathrm{~m}<\text { Turnover } \leq \\
€ 300 \mathrm{~m}\end{array}$ & \\
\hline Very large & 17 & 16.7 & Turnover $>€ 300 \mathrm{~m}$ & \\
\hline \multicolumn{5}{|l|}{ Industrial sector } \\
\hline Manufacture of machinery and equipment n.e.c. & 45 & 43.7 & NACE 28 & \\
\hline $\begin{array}{l}\text { Manufacture of fabricated metal products, except } \\
\text { machinery and equipment }\end{array}$ & 15 & 14.6 & NACE 25 & \\
\hline Manufacture of basic metals & 10 & 9.7 & NACE 24 & \\
\hline Manufacture of motor vehicles, trailers and semi-trailers & 8 & 7.8 & NACE 29 & \\
\hline $\begin{array}{l}\text { Manufacture of computer, electronic and optical } \\
\text { products }\end{array}$ & 3 & 2.9 & NACE 26 & \\
\hline Manufacture of electrical equipment & 3 & 2.9 & NACE 27 & \\
\hline Manufacture of furniture & 3 & 2.9 & NACE 31 & \\
\hline Manufacture of rubber and plastic products & 3 & 2.9 & NACE 22 & \\
\hline Manufacture of textiles & 3 & 2.9 & NACE 13 & Table 1. \\
\hline Manufacture of chemicals and chemical products & 2 & 1.9 & NACE 20 & Description of \\
\hline Manufacture of food products & 2 & 1.9 & NACE 10 & surveyed sample \\
\hline Other manufacturing & 5 & 4.9 & Other & in 2020 \\
\hline
\end{tabular}

The road towards industry 4.0 


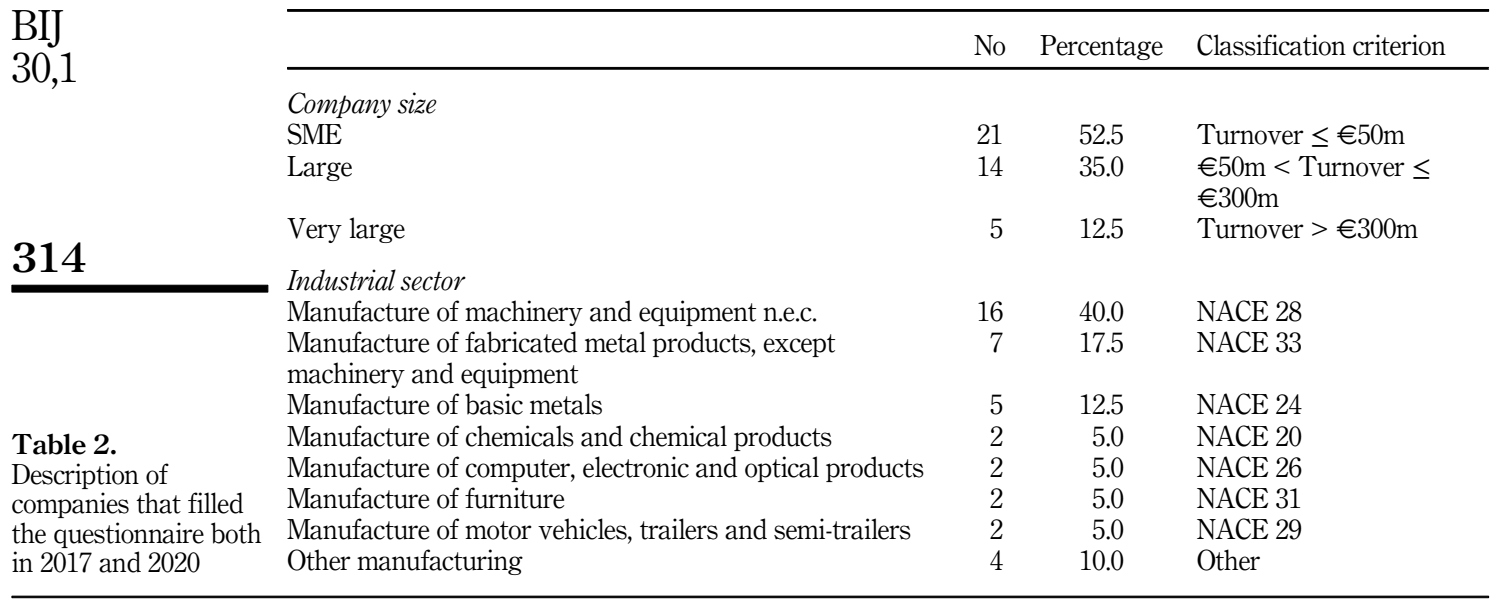

directors, $25 \%$ are top management, managers and associates formulate the other 20 and $18 \%$ respectively.

\subsection{Variables used for analysis}

An overview of the variables adopted for the analysis and their characteristics is shown in Table 3. The variable "Company size" follows the classification already depicted in Table 1.

The variable "Current information systems coverage level" evaluates the company's informatisation level built upon the number of IT systems used, namely: Enterprise Resource Planning (ERP), Customer Relationship Management (CRM), Manufacturing Execution System (MES), Advanced Production Scheduling (APS), Product Lifecycle Management (PLM), Warehouse Management System (WMS), Business Intelligence (BI) and ComputerAided Design/Manufacturing (CAD/CAM). The number of adopted IT systems lower than three corresponds to low, the number of adopted IT systems between three to five corresponds to medium, and more than five is classified in the high cluster.

Concerning "I4.0 technology adoption level", companies that are not aware of the technology are levelled "no knowledge", "no action" means that although companies know the technology, no actions are taken accordingly, "preliminary study" means that companies started to conduct an economical and technical feasibility analysis of the technology, "implementation in progress", "in use", "used and then abandoned" indicates simply the usage stage of the technology.

\begin{tabular}{|c|c|c|c|}
\hline Variable & Type & $\begin{array}{l}\text { No. of } \\
\text { levels }\end{array}$ & Levels \\
\hline Company size & Categoric & 3 & SME; large; Very large \\
\hline $\begin{array}{l}\text { Current information } \\
\text { systems coverage level }\end{array}$ & Ordinal & 3 & Low; Medium; High \\
\hline $\begin{array}{l}\text { I4.0 technology adoption } \\
\text { level }\end{array}$ & Categoric & 3 & $\begin{array}{l}\text { No knowledge; No action; Preliminary study; } \\
\text { Implementation in progress; In use; Used and then } \\
\text { abandoned }\end{array}$ \\
\hline $\begin{array}{l}\text { Business function } \\
\text { involvement level }\end{array}$ & Ordinal & 4 & Null; low; Medium; High \\
\hline Benefit & Ordinal & 4 & Null; low; Medium; High \\
\hline Obstacle & Ordinal & 4 & Null; low; Medium; High \\
\hline
\end{tabular}

Table 3.

Definition and criteria of variables olvement level

Benefit 
To clarify, the authors investigated six I4.0 enabling technologies in the survey of 2017, which are Industrial Internet of Things (IIoT). Big data and analytics (BDA), Cloud manufacturing (CMfg), Augmented and virtual reality (AR and VR), Collaborative robotics and Additive Manufacturing (AM), while in the survey of 2020, CMfg was replaced by Artificial Intelligence (AI). Indeed, for the state-of-the-art study in 2020, six newly determined technologies are analysed, comprising AI. Only five technologies are concerned for longitudinal comparative studies in 2017 and 2020 since AI and CMfg are excluded.

The "business function involvement" variable evaluates the involvement of each company business function in the adoption of the single I4.0 enabling technology. Since each technology investigated four levels of involvement (from 0-null to 3-high) of each business function, the authors also introduced an involvement index that is the mean value of the numbers obtained by each business function for all the technologies adopted by the company.

For "Benefit", the authors investigated four types of benefits: cost reduction, time reduction, quality improvement and flexibility improvement. For "Obstacle", seven types of obstacles are studied, namely lack of awareness for estimating benefits brought by technology, current infrastructure limitation, high investment for hardware and software, high investment for competencies acquire and development, limited commitment from business partners in the supply chain, absence of adequate technology provider and lack of maturity and reliability of the technology. A four-level scale is used for both benefits and obstacles ranging from null to high; thus, an "index variable" is introduced to facilitate the analysis, the mean of the values of the investigated technologies.

To simplify the reading of the results for the reader, the representation of some of the research results will be done by using three different clusters for surveyed companies, namely "no technology in use", "one technology in use" and "at least two technologies in use". For the comparative longitudinal study analysis, the distribution of technology adoption level is drawn similarly.

For the state-of-the-art data analysis in 2020, the company's degree of adoption for six I4.0 enabling technologies is first mapped descriptively. Then factors related to the adoption level of I4.0 technologies are detected and verified through Fisher's exact test, which is adequate to analyse the contingency table regardless of sample size (Bower, 2003; Tabachnick et al., 2007).

Then, the difference between 2017 and 2020 regarding business function involvement, benefits, and obstacles is estimated using Hedge's g value, which is suitable for telling how much one group differs from another when the sample size is small (Cohen, 1962; Ellis, 2010).

The authors also evaluated non-response biases. Indeed, the main criticalities related to web-based surveys are patterns of non-participation and non-response bias (Couper, 2000; Ritter and Sue, 2007). Non-response bias might emerge in potential differences between respondents and non-respondents (Singleton and Straits, 2012). If respondents differ from non-respondents, results could be erratic and distorted (Wagner and Kemmerling, 2010). Generally, this kind of bias can be solved by comparing responses from early and late respondents. Late respondents may be assumed to be most similar to non-respondents because their replies were induced through phone calls or took the longest time (Schniederjans, 2017). Therefore, the authors carried out a comparative analysis between these two groups of respondents. No substantial non-response bias issues were encountered.

The analysis of the results was carried out through the adoption of Microsoft Excel and $\mathrm{R}$ software for arranging statistical analysis.

\section{Results}

4.1 What is the state-of-the-art impact of industry 4.0 on Italian manufacturing companies?

To answer RQ1, the investigation focuses on the I4.0 enabling technologies' adoption level in 2020 and explores the factors that affect their utilisation, the benefits perceived by the companies and the obstacles encountered. As shown in Figure 2, companies are found to have 
BIJ 30,1

\section{6}

Figure 2.

I4.0 enabling technologies' utilisation distribution

Figure 3.

Relationship between company size and number of $\mathrm{I} 4.0$ enabling technologies in use varying awareness and approaches towards I4.0 technologies. IIoT is the best-known technology among the six investigated technologies, while AI is the least familiar one. In particular, $66 \%$ of the surveyed sample declare to be conscious of IIoT, and this proportion is only $26 \%$ for AI. Besides, only $3 \%$ of the surveyed companies have not taken action though they know it, while this ratio is about $10 \%$ for the other five technologies. Indeed, the proportion of companies conducting preliminary analysis for IIoT is also the highest, amounting to $28 \%$, compared to a range between 12 and $16 \%$ for the other technologies. However, AM is the most adopted technology, with $23 \%$ of the companies putting it into practice, and IIoT is the second most widely used technology. In contrast, AI, AR and VR are rarely adopted, with only 1 and $5 \%$ utilisation, respectively.

Figure 3 draws the relationship between company size and the number of I4.0 enabling technologies adopted by the companies. To make this analysis more straightforward, we have divided the sample into three main clusters: (1) companies that do not adopt any technology; (2) companies that adopt only one technology; and (3) companies that adopt at
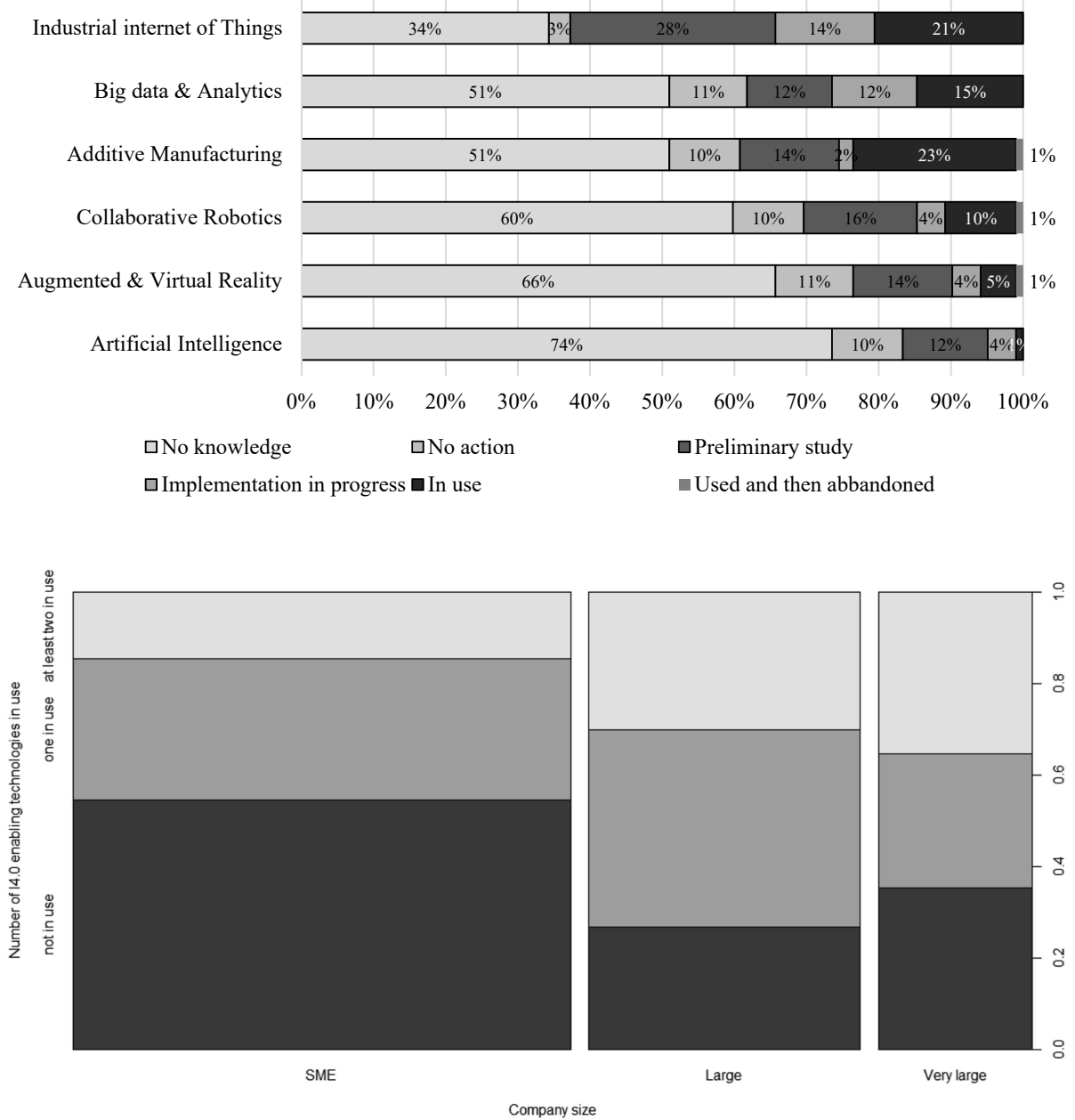
least two technologies. It is shown that the larger the company size, the greater the number of technologies adopted by the company. The distinction between large-sized (and very largesized) companies and SMEs is very significant. More than $70 \%$ of large companies adopt at least one I4.0 technology, and over 30\% use at least two. This trend, albeit to a lesser extent, is also confirmed by the analysis of very large companies. The significance of the association between the variables was evaluated with Fisher's exact test ( $\phi$-value $=0.02169)$, confirming a significant association.

Figure 4 draws the relationship between the company's current information system coverage level and the number of I4.0 enabling technologies implemented. It can be observed that with a high level of informatisation, companies tend to use more I4.0 technologies. Actually, for companies with a low information system coverage level, none of them has adopted more than one technology, while for companies with a medium information system coverage level, the proportion of companies that adopt one technology accounts for around $40 \%$, and more than $20 \%$ of them are adopting at least two technologies. Moreover, concerning companies with high information system coverage levels, the ratio for adopting at least two technologies corresponds to slightly over $40 \%$. Fisher's exact test gives the $p$-value $=0.0004974$, verifying the significant association of these two variables.

Figure 5 shows the involvement of different business functions regarding the adoption of I4.0 enabling technologies. In this analysis, of course, we have excluded the cluster of companies that have not adopted any technology. The involvement level is generally higher with the increase in the number of technologies in use by the company, except for marketing. Overall, the involvement level is extended from around 0.8 to 2.2 , indicating a range from very low to above medium level. It can be observed that among all the business functions, R\&D, production and IT are the three most involved areas. As regards R\&D, it is highly involved regardless of the number of technologies in use. This business function usually involves activities dedicated to innovation and introduction of new products and services, investigating the new technologies, and constantly being involved in technology evaluation and implementation. Concerning production, as it is responsible for goods manufacturing and is also the area where most I4.0 technologies are applied, it is not surprising to observe its high involvement. Considering that IT guarantees the smooth function of the network and IT infrastructure, and the I4.0 technologies are digitally in nature, its involvement is also rational.

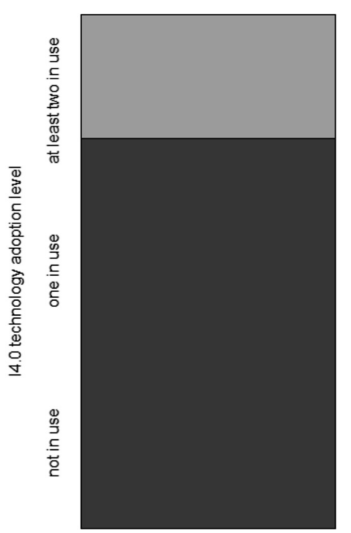

low

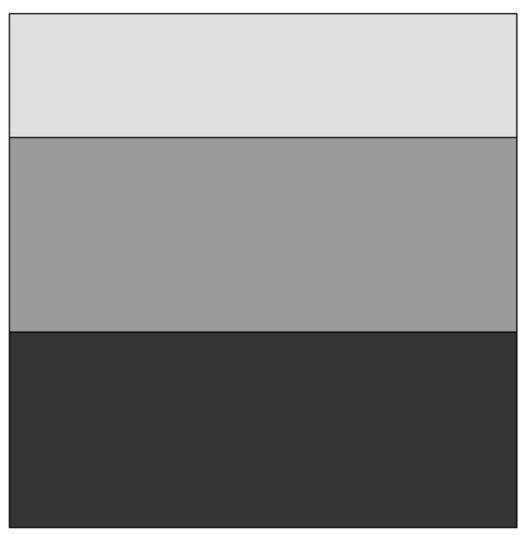

medium

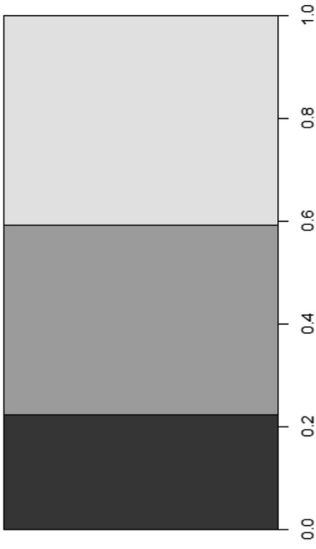

high
Figure 4.

Relationship between company's current information system coverage level and number of I4.0 enabling technologies in use 
BIJ

30,1

\section{8}

Figure 5.

Business function involvement

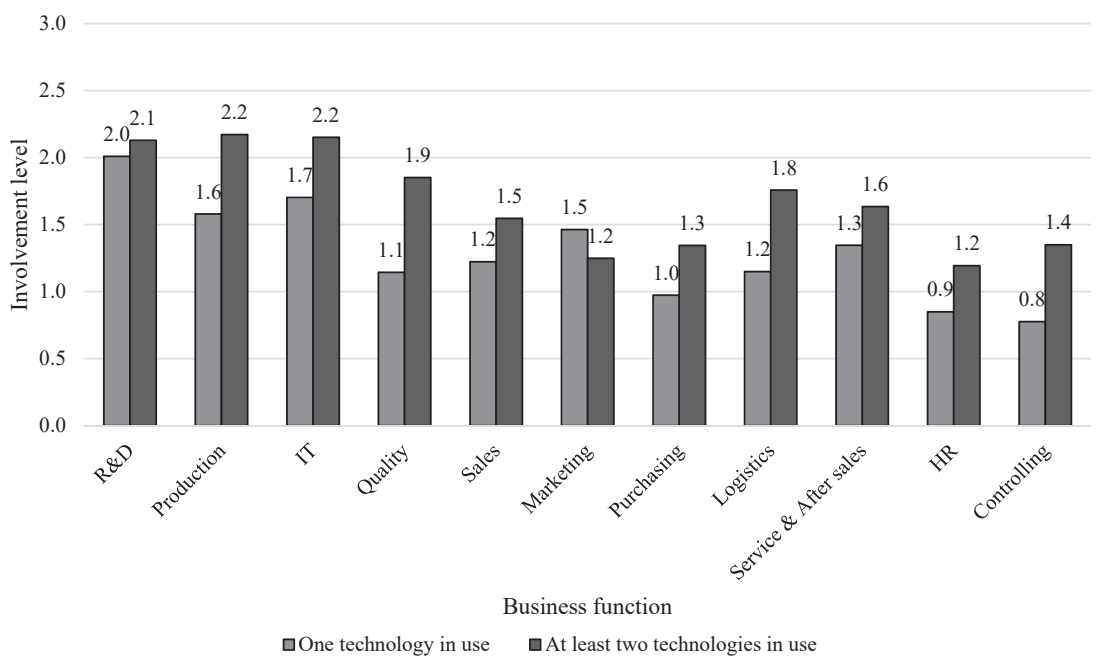

Moreover, we observe a high involvement concerning Quality, Logistics, and Service and After sales functions, especially in the case that at least two technologies are in use, which demonstrates a good signal that the potential of I4.0 enabling technologies is covering broader business processes. On the contrary, it can be seen that for Purchasing, HR and Controlling, the involvement level keeps a relatively low position. However, in this case, when the number of technologies in use is at least two, their involvement is also significantly increased.

In the next step, the authors depict the benefits pursued or achieved from implementing I4.0 enabling technologies and the obstacles feared and faced by the companies (Figures 3 and 4). Concerning the analysis of benefits and obstacles, a clarification is necessary. Regarding benefits, for companies that do not adopt any technology, they are to be interpreted as desirable, while for the other two clusters, the benefits are to be considered "achieved". The same reasoning applies to obstacles. In the first case, these are feared obstacles, while in the second case, reference is made to obstacles faced.

Figure 6 illustrates that the more the number of technologies used, the higher the perceived benefit level overall. In general, the benefit obtained by companies that have implemented at least one technology is always higher than that desired by companies that have taken no action. Among the four investigated benefits, cost reduction is considered the most significant benefit desirable or brought about by adopting I4.0 technologies. Indeed, companies that have implemented at least one technology have experienced higher benefits compared to other companies. Another interesting finding is that time reduction, and Quality/ service improvement are also believed to be generated by I4.0 technologies. This indicates that companies utilise digitalised solutions as levers to reduce the time-to-market cycle and deliver high-quality products and services. In particular, the benefit intensity is much higher for companies that have adopted more than one technology than those that have adopted only one.

Figure 7 shows the results concerning obstacles feared or faced by companies when implementing I4.0 enabling technologies. In general, high investment for competencies acquisition and development is positioned first. For companies that have adopted more than two technologies, the competency issue is even more in evidence, regarding lack of awareness for estimating benefits brought by technology, limited commitment from a business partner 


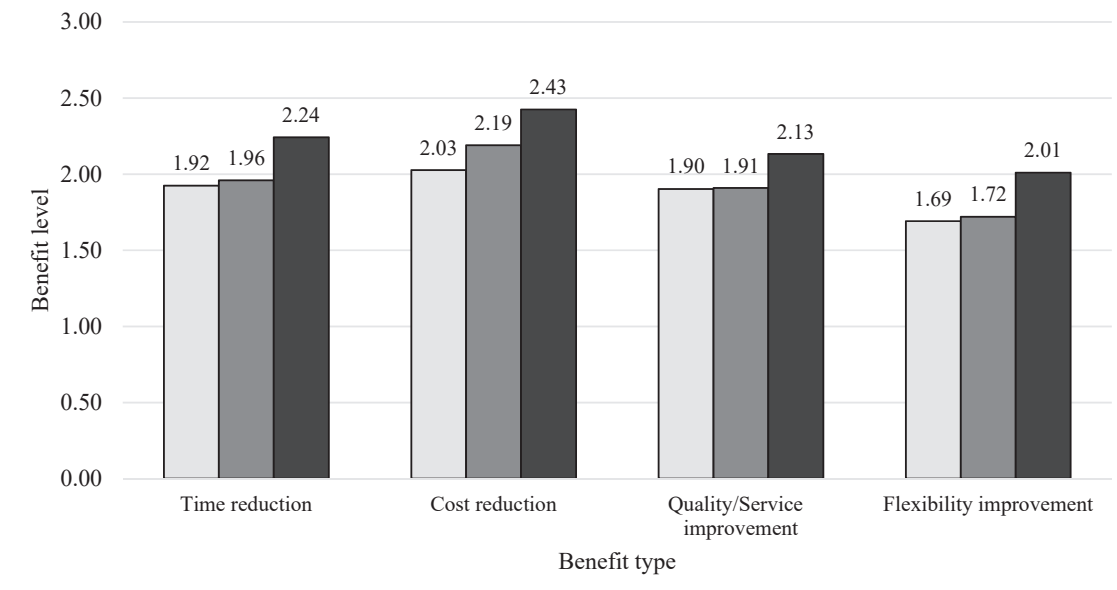

$\square$ No technology in use
-At least two technologies in use
The road towards industry 4.0

Figure 6. Benefits perceived by companies by adopting I4.0 enabling technologies

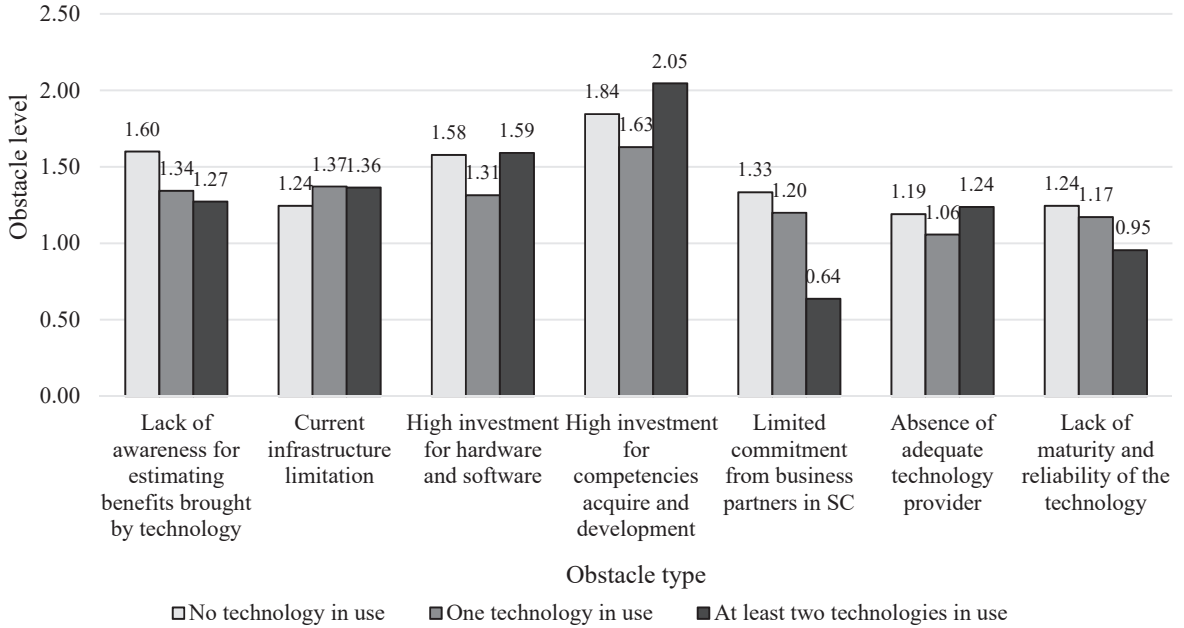

Figure 7.

Obstacles faced by companies when adopting I4.0 enabling technologies

in the supply chain, and lack of maturity and reliability of the technology. The more the number of technologies in use, the less the intensity of the obstacle experienced by the company. Concerning these specific obstacles, a trend of this kind is because companies, once they have embarked on the path of digital transformation, realise that the fears they previously had were mainly due to a lack of knowledge about certain peculiar aspects.

Moreover, the lower value for companies that have adopted more than one technology stems from the fact that they have gained more maturity over time in implementing technologies. However, there are other obstacles with a U-shape trend: a high obstacle value for companies that have not adopted any technology and companies that have adopted more than one technology, while a lower value for companies that have adopted only one 
BIJ 30,1

320

technology. As shown by the figure, these obstacles mainly refer to areas mainly related to technological aspects (high investment for hardware and software, absence of adequate technology provider), and such a trend may be due to the difficulties of integration between the various technologies when deciding to adopt more than one technology. The same trend also characterises the investment needed for acquiring and developing competencies. Finally, concerning current infrastructure limitations, the obstacle faced is slightly higher than anticipated before adopting one or more technologies. This situation depends on the fact that the current technical and technological infrastructure that must support the new digital technologies is sometimes underestimated.

\subsection{What are the main 14.0 implementation variations concerning technologies} implemented, business functions involved, perceived benefits and obstacles encountered? In this section, we compare the state-of-the-art I4.0 impacts in the Italian manufacturing companies in 2020 to 2017 from the perspectives of I4.0 enabling technologies' adoption distribution, the involvement of diverse business functions, perceived benefits and obstacles faced.

As shown in Figure 8, compared to 2017, companies are more aware of the technologies. Such a signal is evident for some specific technologies like BDA, with a reduction of 23 percentage points concerning 2017 referring to the no knowledge cluster. Regarding the other technologies, the percentage of companies who do not know the technologies has decreased by more than ten percentage points. On the other hand, it can be observed that more companies are adopting I4.0 solutions in 2020 compared to 2017, with a significant increase for IIoT and BDA, which separately counts an increase of 17 and 15 percentage points. In addition, the proportion of companies that have moved to implement these two technologies has also increased. Besides, there is an increase of 10 percentage points of companies using $\mathrm{AM}$, while for $\mathrm{CR}$ and $\mathrm{AR}$ and $\mathrm{VR}$, the increase rate is relatively stable. However, more companies have begun to conduct a preliminary analysis of these two technologies. Therefore, it can be stated that the evolution of adopting the 4.0 paradigm is proceeding concretely, although more significant trends than others characterise some technologies.

Figure 8.

I4.0 enabling technologies' adoption level comparison

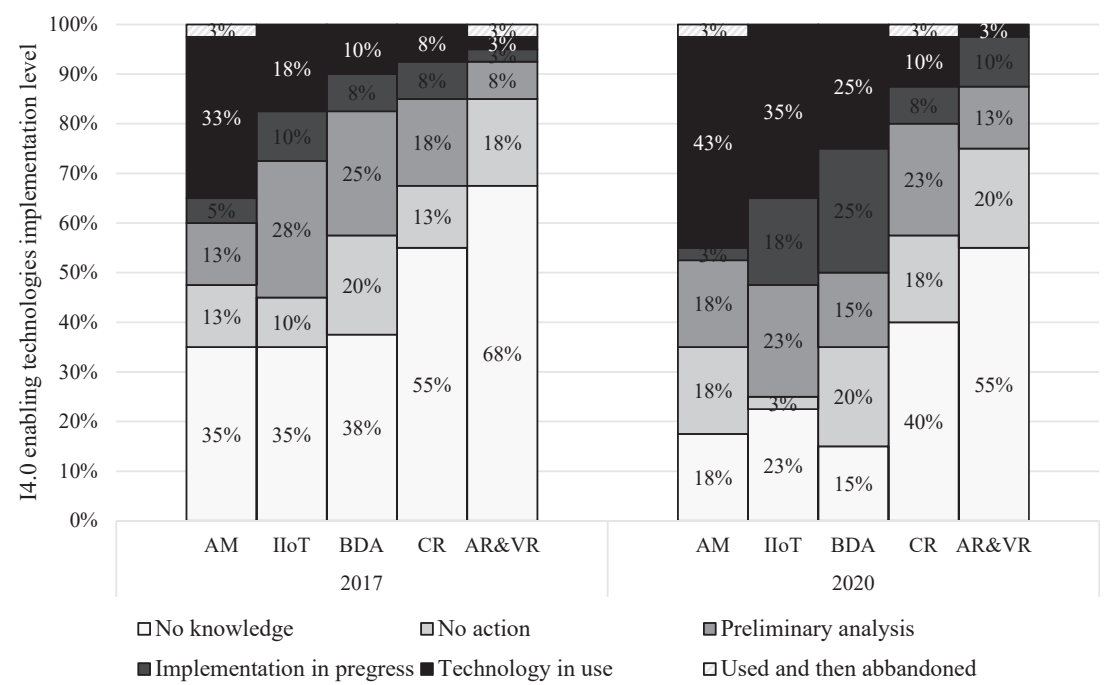


The analysis and comparison of different business functions involved in introducing I4.0 enabling technologies have also been investigated. It is shown in Figure 9 that there is an increasing trend of involvement level of almost all the business functions in 2020, except for the sales function, which keeps the same value. Among all the business functions, Production, R\&D and IT are still rated as the three most involved functions in 2020. At the same time, although the involvement of the human resources function has increased from 0.95 to 1.16 , it still came in last place in 2020. A Hedge's $g$ test has been conducted to verify whether there is a difference between means of two groups, with a general guideline of 0.2 for a small effect, 0.5 for a moderate effect, and 0.8 for a significant effect (Cohen, 2013). In this regard, the logistics function has the largest Hedge's $g$ value of 0.71, implying an evident increase of involvement in 2020. Quality, R\&D, IT, Service and Aftersales function have the Hedge's g values as 0.53, 0.45, 0.46, 0.46, respectively, representing a moderate difference between 2017 and 2020, while for other functions, the Hedge's $g$ value is between 0.1 and 0.5 , which indicates a relatively low effect.

The comparison of benefits and obstacles from implementing I4.0 enabling technologies are separately shown in Figure 10 and Figure 11.

Several changes have been detected comparing 2017 and 2020. Regarding benefits, companies perceive higher benefits in 2020 than in 2017 . However, for all four types of benefits investigated in this study, the most significant benefit from adopting I4.0 technologies is cost reduction, followed by time reduction, which has the value of 2.1 and 2.2 separately, compared to that of 1.7 in 2017. The Hedge's $g$ values are 0.55 and 0.42 , demonstrating a moderate difference between the two means. Moreover, it was found that for quality improvement and flexibility improvement, the companies are also shown to obtain higher levels of benefits in 2020 compared to 2017, with Hedge's g values of 0.48 and 0.46 , respectively, showing moderate effects. Indeed, the higher benefits perceived by companies in 2020 are not difficult to foresee. As shown in the previous analysis, there is a positive relationship between the benefits level and the number of technologies in use. Since more companies are putting I4.0 technologies into use in 2020, they are accordingly obtaining more benefits.

Figure 11 shows the comparison of obstacles faced by companies. The Hedge's g values ranged from 0.14 to 0.29 , implying minor differences between 2017 and 2020. In 2020, the highest obstacle level lay in the high investment in competencies acquired and developed.

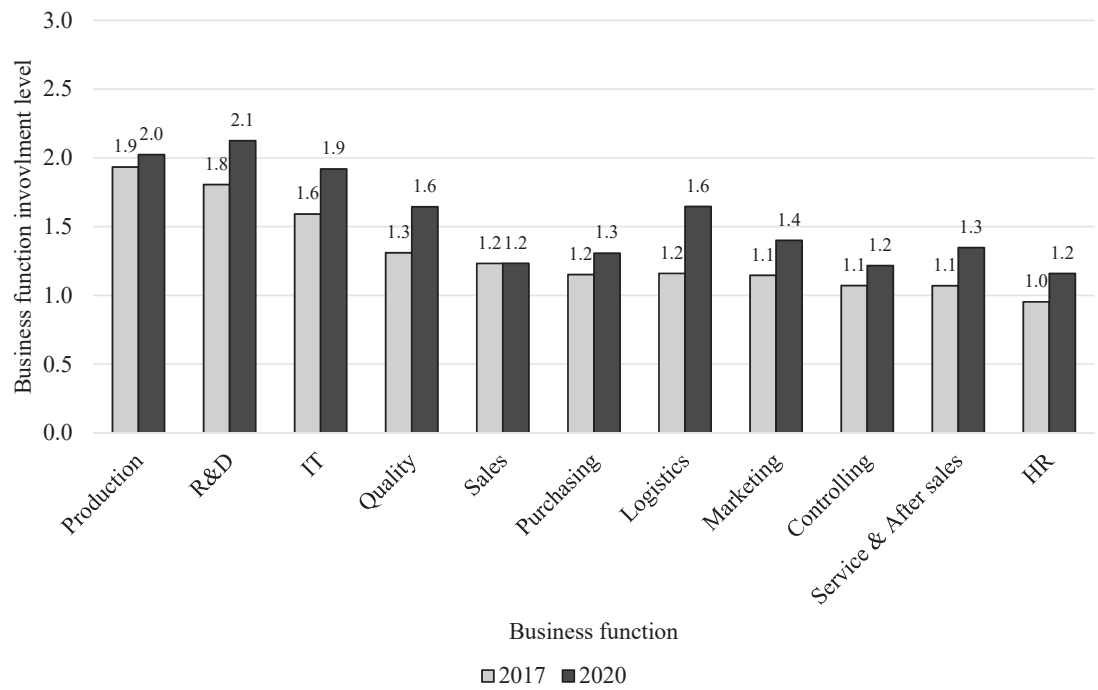

The road towards industry 4.0
Figure 9. Business function involvement comparison 
BIJ

30,1

\section{2}

Figure 10.

Perceived benefits comparison
Figure 11.

Faced obstacles comparison $\square 2017 \square 2020$

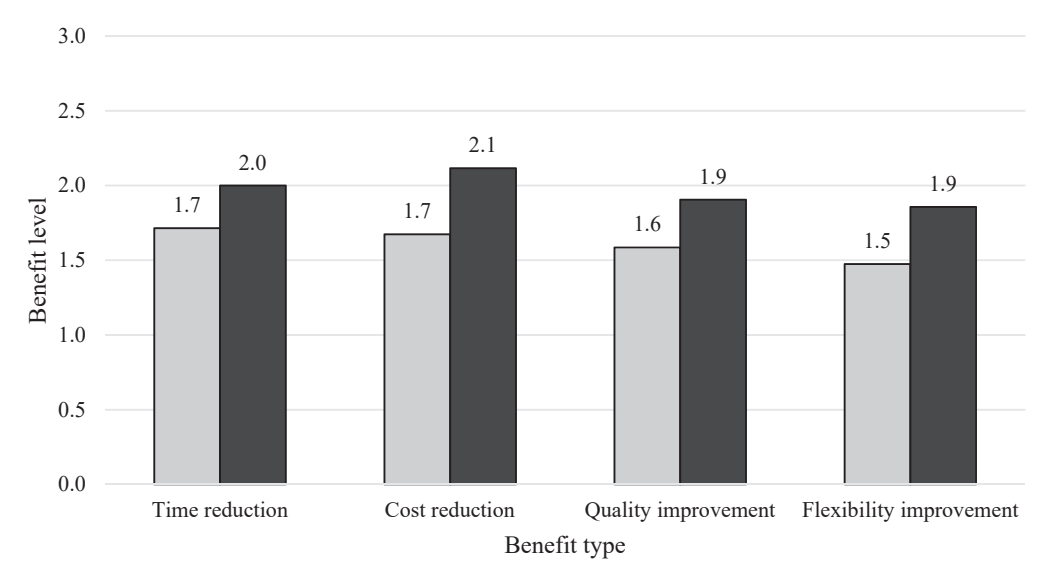

$3.0 \longrightarrow 20170$

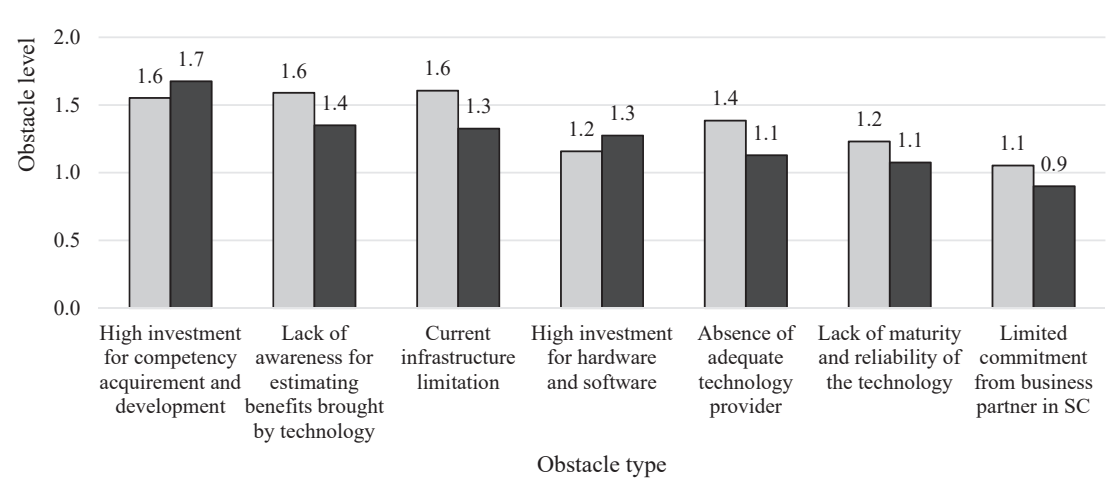

$\square 2017 \square 2020$

Indeed, acquiring adequate competencies continues to be a barrier for companies from 2017 to 2020. Such results indicate that skilled professionals are necessary in the I4.0 manufacturing context, and companies regard it as one of the most significant barriers. Another obstacle that has a higher value in 2020 is a high investment in hardware and software. Such an observation can be explained by the fact that since more technologies were being implemented in 2020, it requires more physical and human resources investment. Apart from these two investment-related obstacles, all the other obstacles are overserved to have lower value in 2020 compared to 2017. Concerning the lack of awareness for estimating benefits brought by technology, since companies are more aware of the I4.0 technologies and are obtaining more benefits by adopting them, the decrease of obstacle level is rational.

Regarding the decline of obstacle level regarding limited infrastructure, the explanation could be that more companies in 2020 are putting efforts into adopting I4.0 technologies; thus, 
the existing infrastructure is also updated to be connected and integrated to the usage of novel technologies. Besides, for the decrease of impact of the Absence of technology providers and Lack of maturity and reliability of the technology in 2020, it is reasonable to say that the technologies are even more mature and powerful, and it is relatively easy to find potential providers; thus, they are no longer a big issue for the companies. Moreover, for a limited commitment from business partners in SC, the comparison reveals that the internal motivation of the organisation more orients the implementation of I4.0 solutions, and partners along the supply chain are not giving hinders for such implementation.

\section{Discussion}

First, the empirical results demonstrate that the effective adoption of I4.0 enabling technologies is overall poor within the Italian manufacturing sector. Such observation is more evident for technologies like AR and VR and AI. Both were adopted by less than $5 \%$ of the companies, while for IIoT and AM, the adoption status is better, with more than $20 \%$ of surveyed companies putting them into practice. Therefore, it demonstrates that Italian manufacturing companies are not fully embracing the I4.0 journey, and the explanation of the low adoption level can be two-fold. First, a company's technology strategy is a long-term evolutionary process and not a "one-fell-swoop" choice (Lefebvre et al., 1992). In particular, I4.0 is still a relatively new phenomenon, and enabling technologies are evolving (Klingenberg et al., 2019). It is thus reasonable to see that companies are more familiar with some specific technologies than others, such as IIoT and AM, which have acquired a higher level of maturity than the others. Second, implementing I4.0 technologies calls for technological and organisational alteration, such as retrofitting existing production systems and equipment, which is also a critical challenge for companies to rapidly implement the technologies (Veile et al., 2019). Indeed, the results of this study also show that firm size and a company's current information system coverage level are related to the adoption of I4.0 technologies. As SMEs usually are struggling with the time to learn about the I4.0 technologies and the funding to implement them (Masood and Sonntag, 2020), it is not a surprise to see that firm size is a significant predictor of I4.0 adoption, which has already been proved by several previous studies (Gomez and Vargas, 2009; Müller et al., 2018). At the same time, companies with higher information systems coverage levels tend to implement more technologies. This result indicates that IT maturity seems to be one of the fundamental boosters for I4.0 technology adoption. Companies would have more know-how about organisational information exchange to favour vertical and horizontal digital integration (Pirola et al., 2019). Another interesting finding is derived from the comparative longitudinal results, demonstrating that the companies are gradually more aware of the technologies. Indeed, there is a remarkable increase with regards to the adoption of IIoT and BDA. This result indicates a positive sign: although implementing I4.0 technologies demands time, resources and upgrade of existing infrastructure, companies are making efforts to understand what the technology is and try to use it in different application fields. Undeniably, the increased use of IIoT and BDA may also reflect that companies seek integrated I4.0 technologies used towards data-driven solutions (Zheng et al., 2021). In the meantime, the adoption of $\mathrm{CR}$ and $\mathrm{AR}$ and VR does not appear to increase since the companies are demonstrated to have less knowledge about these technologies, which may prevent them from implementation without evaluating the technical and economic feasibility (Zheng et al., 2019).

Concerning the involvement of different business functions in the I4.0 transformation journey, our findings suggest two conclusions. First, R\&D, production, and IT are more involved than other functions, while HR is the lowest involved area. This result shows an unbalanced penetration of I4.0. Indeed, the high involvement of production is not difficult to predict since the core business of a manufacturing company is goods manufacture, and the production function is responsible for transforming the raw material to the final product (Zheng et al., 2019). The high involvement of R\&D and IT is also reasonable because
The road towards industry 4.0 
BIJ

30,1

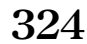

companies have limited knowledge of the I4.0 enabling technologies, and the access and evaluation of novel technology are related to R\&D activities.

Notwithstanding, the long-lasting low involvement of HR is evidence that cannot go unnoticed since qualification and training of employees is relevant in a changing digital context (Hecklau et al., 2016). However, the good sign is that when more I4.0 technologies are implemented in the company, the HR function is more involved, which reflects that the role of $\mathrm{HR}$ is increasingly valued. Second, the comparative results show that almost all the business functions are more involved in 2020 compared to 2017, among which the Logistics and Quality functions are even more evident. This may indicate that adopting I4.0 enabling technologies is broadening its impact in more business functions, focused on production, IT, and R\&D, and seeking their applications in the other areas.

Focusing on the benefits obtained by adopting I4.0 enabling technologies, the results suggest three main conclusions. First, overall benefits perception appears to be related to the number of technologies in use by the companies. As Masood and Sonntag (2020) discussed, the benefit seems to be a facilitator for I4.0 adoption, while the results of our findings demonstrate a biunivocal relationship. Most plausibly, the link between benefits and I4.0 technology adoption may be bidirectional. In other words, on the one hand, companies that tend to consider higher benefits are likely to implement more technologies.

On the other hand, through implementing I4.0 technologies, companies are placed in a much better competitive position, which makes them perceive more benefits. Second, among the four investigated benefits, cost reduction is still prominent concerning the others. This finding could provide practical insights into the performance objective targeted by other researchers (Moeuf et al., 2018). Although several studies dissert about I4.0 solutions for improving flexibility (Masood and Sonntag, 2020; Szász et al., 2021), companies still consider cost reduction the highest benefit brought by adopting I4.0 technologies. Indeed, the third conclusion derived from longitudinal results is that companies are obtaining more benefits after a three-year interval, and the evident increase is related to cost reduction and quality improvement. This result is also aligned with the fact that the adoption level of I4.0 technologies is higher in 2020 compared to 2017 and proves the bidirectional relationship between I4.0 technology adoption and perceived benefits. Although cost reduction and quality improvement seem to be two contradictory benefits, they are the main contributions of I4.0 enabling technologies, which enable the delivery of high-quality product/service with reduced cost, and that can be considered one of the potential elements to pursue by Italian manufacturing companies (Buckley and Strange, 2015; Strange and Zucchella, 2017).

Concerning the obstacles faced by the companies, our results suggest two main conclusions. First, it appears that the obstacles expected by the companies are generally more significant than what companies are encountered with, and the impact of obstacles is generally lower than the beneficial ones. This demonstrates that companies are favourable in adopting I4.0 technologies, and with more technologies adopted, benefits brought by technology seem to override the barriers. This finding is similar to those figured out by Müller et al. (2018). They argue that implementing I4.0 can provide far-reaching benefits and opportunities that dominate the risks. Thus, companies should not be discouraged from pursuing digitisation. Indeed, this argument is also confirmed by the previous discussion about the benefit. The second conclusion refers to the obstacles of high investment for competencies acquisition and development, which is one of the biggest obstacles. Indeed, the comparative results show that companies consider it a more significant barrier in 2020 concerning 2017. This phenomenon explains that the early adoption decision of novel technologies requires companies to develop technological and organisational skills and capabilities that could ensure the smooth and efficient operation of the technology (Lefebvre et al., 1992). However, in our context, it appears that pursuing and developing qualified expertise is an issue for the companies, and in fact, the involvement of $\mathrm{HR}$ in the introduction 
and adoption of technology has been illustrated below; as a consequence, companies may lose the opportunity of accumulating knowledge and expertise on the technology and may fall behind to its direct rivals (Bhatt and Grover, 2005).

Moreover, the external barriers, such as the limited commitment from business partners, the absence of an adequate technology provider, and lack of maturity and reliability of the technology, are considered more minor obstacles than the internal barriers. This finding indicates that with the progressing development of I4.0, the market could offer more mature technological solutions. The business partners are generally in favour of the adoption of I4.0 enabling technologies. Thus, companies should focus on finding and developing adequate competencies (Fareri et al., 2020).

\section{Conclusions}

The debate on how I4.0 is implemented in manufacturing companies has become increasingly popular and is still ongoing in the literature. In particular, the literature provides many contributions concerning analysing the state of adoption of the I4.0 paradigm in manufacturing companies in different geographical areas. Many of these studies focus on the level of implementation of enabling technologies, the benefits achieved and the factors inhibiting adoption. Although several efforts have been made to understand the status of I4.0 implementation in diverse countries, including industrialised and emerging economies (Birkel et al., 2019; Bosman et al., 2019; Tortorella et al., 2021; Tortorella and Fettermann, 2018), investigation of the "big picture" of I4.0 implementation and its advancing status are deemed to be necessary to bridge the gap between the potential of I4.0 and its actual application in the real world. Moreover, the literature highlights the lack of longitudinal studies to investigate the evolution in adopting I4.0 technologies. Another aspect that needs more study is inherent in the evolution of benefits and barriers. Hence, this study provides results for two main research questions. The first one (RQ1) considers the state-of-the-art impact of I4.0 on Italian manufacturing companies.

In contrast, the second (RQ2) concerns the main I4.0 implementation variations concerning technologies implemented, business functions involved, perceived benefits and obstacles encountered. The set objectives are achieved by analysing two empirical surveys carried out on Italian manufacturing companies three years apart. In particular, the longitudinal study was carried out on a sub-sample common to both surveys characterised by 40 respondents. The analysis of the results of this research shows that there is a significant improvement in the adoption of the paradigm, with increasing involvement of all business functions. Similarly, the perceived benefits of digital technology applications for manufacturers are growing. Besides, the perceived obstacle to the maturity level of the technologies and the difficulties inherent in integration is diminishing. At the same time, there is greater sensitivity to the economic and financial investments required to acquire the necessary technologies and skills.

\section{Implications, limitations and future research \\ 7.1 Theoretical implications}

The contribution of this study is two-fold. First, it augments empirical insight into Italian manufacturing companies through a survey with 102 validated samples, describing the stateof-the-art of I4.0 from the perspectives of technology adoption state, business function involvement, perceived benefits, and obstacles encountered. Second, based on a two-wave longitudinal study with a three-year interval, a comparative study is conducted based on a sample of 40 companies, attempting to figure out the main I4.0 implementation variations. The state-of-the-art investigation shows that Italian manufacturing companies have limited knowledge of I4.0 enabling technologies. The adoption level differs per technology, whereby IIoT and AM are relatively highly used.
The road towards industry 4.0 
BIJ

30,1

326

In contrast, the adoption of $\mathrm{AR}$ and $\mathrm{VR}$ and $\mathrm{AI}$ is still very immature. Indeed, the adoption level of I4.0 enabling technologies is uneven to SMEs and large companies, as larger companies are found to have a higher adoption rate, reflecting the struggling status of SMEs regarding I4.0 solution implementation. Our result also reveals that more informatized companies have a higher adoption level of I4.0 enabling technologies, indicating that a mature IT infrastructure may positively impact further digital technology adoption. Moreover, an unbalanced involvement of business functions regarding I4.0 adoption is also detected, where Production, IT and R\&D are highly involved, while HR comes in the last place. This result is in line with the perceived threat to businesses to align staff skills to make the most of the digital revolution.

Furthermore, implementation of more than one I4.0 technology means higher involvement of business functions and vice versa. Regarding the benefits and obstacles investigated in this study, on the one hand, our study shows that companies are seeking more to adopt I4.0 technologies by reducing cost. On the other hand, companies' highest obstacles concern acquiring and developing adequate competencies for implementing and effectively using I4.0 solutions.

At the same time, our comparative study has made the first attempt to figure out how Italian manufacturing companies are moving forward to I4.0. The results firstly demonstrate that companies are more aware of the I4.0 enabling technologies after a three-year interval, and putting more practically in I4.0 solutions adoption; meanwhile, the involvement of different business functions is overall higher, particularly for Quality and Logistics functions, implying a wider penetration of I4.0 adoption. Moreover, our study confirms that cost reduction is still the most significant benefit brought by I4.0. In contrast, other benefits such as time reduction, quality improvement and flexibility improvement are all pursued by companies. Furthermore, the need for skilled competencies becomes even more crucial for companies. Since the overall I4.0 adoption level was higher in 2020, a highly qualified workforce is more demanded to evaluate and implement I4.0 solutions.

\subsection{Practical implications}

The results presented in this article could provide several practical insights for manufacturing companies and practitioners. First, our results indicate that the adoption of I4.0 technologies varies upon technology, and more companies are implementing new technologies is also evident. Thus, the need for putting more I4.0 technologies into use within Italian manufacturing companies seems inevitable to achieve a higher level of benefits. However, the involvement of business functions varies regarding I4.0 technology adoption, reflecting that companies have different priorities for adopting I4.0 to optimise their processes. Indeed, the findings of benefits perceived by companies reflect the attractiveness of I4.0 technologies, which is to consider cost reduction and lead time reduction as first choices.

Nonetheless, companies are also obtaining higher quality and greater flexibility by adopting I4.0 technologies, and the benefits perceived are often greater than expected. Indeed, companies that have already adopted I4.0 solutions are generally satisfied with the results achieved more than the expectations by the ones adopting no technologies. Thus, companies are suggested to evaluate the potential of I4.0 implementation in more business processes, amplifying the application areas of digital technologies and setting up their technology policies to acquire a competitive advantage. However, attention must be paid to possible obstacles when companies evaluate and implement I4.0 technologies. One of the main difficulties that can undermine the success of I4.0 implementation is the investment in adequate competencies' acquirement and development, which has been a sustained issue for manufacturing companies. Therefore, companies need to evaluate their current workforce, plan proper qualifications, and update technical and managerial competencies to overcome this hurdle. In other words, appropriate staff training and qualification and effective new competency acquisition become necessary to ensure the effective implementation of I4.0 
technologies. Therefore, it is clear that companies need to involve the HR function more closely in the effective digital transformation of their manufacturing processes.

\subsection{Limitations and future research directions}

The research presented in this paper has some limitations. First, the survey in this paper is conducted among Italian manufacturing companies. Thus, it limits the degree to which the findings may be generalised to other countries. Since different countries promote different initiatives for promoting I4.0 transformation, manufacturing companies may be influenced by such policies, thus showing different digitalisation approaches. Indeed, company characteristics may differ among developed and emerging economies (Cheng et al, 2018). For this reason, further research could take into account more international comparisons to obtain more generalised findings.

The second limitation stems from the sampling issue. In our sample, the SMEs account for around $54 \%$. Although it represents the majority of the total sample, it is still not large enough because more than $90 \%$ of the manufacturing companies in Italy are composed of SMEs. Further useful insight in this respect will be the carrying out of case studies aimed at analysing the main peculiarities of SMEs compared to large companies.

Third, a sample of 40 respondents was used in our longitudinal study for comparative analysis, and a two-wave panel design was adopted. Though conducting the longitudinal study usually requires more time and effort, we believe it is worth conducting a more wave longitudinal study and increasing the standard sample size to better catch up with the variations of I4.0 adoption, which will also be consistent with the evolving characteristics of I4.0. This will also include new waves of surveys to continue the longitudinal study.

Fourth, although the authors tried to incorporate the most important I4.0 technologies in the questionnaire, some other important I4.0 enabling technologies (e.g. simulation and modelling, blockchain) are not explicitly mentioned. Therefore, a more detailed survey instrument could help get better insight into the I4.0 development in the next couple of years.

Finally, the authors try to figure out some crucial factors that impact the adoption of I4.0 technologies. At the same time, due to the descriptive nature of this survey and the initial stage of the I4.0 investigation, no reference framework has been proposed. In our future work, more assumptions could be tested to figure out the key factors that lead to the successful implementation of I4.0. Despite the presented limitations, the authors believe that this study reveals valuable insights and implications that serve both research and practice to better understand the I4.0 state-of-the-art in Italian manufacturing companies and the relevant variations on the road towards I4.0.

\section{References}

Ardito, L., Petruzzelli, A.M., Panniello, U. and Garavelli, A.C. (2019), “Towards industry 4.0”, Business Process Management Journal, Emerald Publishing, Vol. 25 No. 2, pp. 323-346.

Ardolino, M., Rapaccini, M., Saccani, N., Gaiardelli, P., Crespi, G. and Ruggeri, C. (2018), "The role of digital technologies for the service transformation of industrial companies", International Journal of Production Research, Vol. 56 No. 6, pp. 2116-2132.

Ashour Pour, M., Zanoni, S., Bacchetti, A., Zanardini, M. and Perona, M. (2019), "Additive manufacturing impacts on a two-level supply chain", International Journal of Systems Science: Operations and Logistics, Taylor \& Francis, Vol. 6 No. 1, pp. 1-14.

Bag, S., Telukdarie, A., Pretorius, J.H.C. and Gupta, S. (2018), "Industry 4.0 and supply chain sustainability: framework and future research directions", Benchmarking: An International Journal, Vol. 28 No. 5, BIJ-03-2018-0056.

Belinski, R., Peixe, A.M.M., Frederico, G.F. and Garza-Reyes, J.A. (2020), "Organizational learning and Industry 4.0: findings from a systematic literature review and research agenda", Benchmarking: An International Journal, Vol. 27 No. 8, pp. 2435-2457.
The road towards industry 4.0

\section{7}


BIJ

30,1

Benotsmane, R., Kovács, G. and Dudás, L. (2019), "Economic, social impacts and operation of smart factories in industry 4.0 focusing on simulation and artificial intelligence of collaborating robots", Social Sciences, Vol. 8 No. 5, p. 143.

Bhatt, G.D. and Grover, V. (2005), "Types of information technology capabilities and their role in competitive advantage: an empirical study", Journal of Management Information Systems, Taylor \& Francis, Vol. 22 No. 2, pp. 253-277.

Bienhaus, F. and Haddud, A. (2018), "Procurement 4.0: factors influencing the digitisation of procurement and supply chains”, Business Process Management Journal, Vol. 24 No. 4, pp. 965-984.

Birkel, H., Veile, J., Müller, J., Hartmann, E. and Voigt, K.-I. (2019), "Development of a risk framework for industry 4.0 in the context of sustainability for established manufacturers", Sustainability, Vol. 11 No. 2, p. 384.

Blanco-Novoa, O., Fernandez-Carames, T.M., Fraga-Lamas, P. and Vilar-Montesinos, M.A. (2018), "A practical evaluation of commercial industrial augmented reality systems in an industry 4.0 shipyard", IEEE Access, Vol. 6, pp. 8201-8218.

Bosman, L., Hartman, N. and Sutherland, J. (2019), "How manufacturing firm characteristics can influence decision making for investing in Industry 4.0 technologies", Journal of Manufacturing Technology Management, Vol. 31 No. 5, pp. 1117-1141.

Bower, K.M. (2003), "When to use Fisher's exact test”, American Society for Quality, Six Sigma Forum Magazine, Vol. 2, pp. 35-37.

Brad, S., Murar, M. and Brad, E. (2018), "Design of smart connected manufacturing resources to enable changeability, reconfigurability and total-cost-of-ownership models in the factory-of-the-future", International Journal of Production Research, Taylor \& Francis, Vol. 56 No. 6, pp. 2269-2291.

Bravi, L. and Murmura, F. (2021), "Industry 4.0 enabling technologies as a tool for the development of a competitive strategy in Italian manufacturing companies", Journal of Engineering and Technology Management, Elsevier B.V., Vol. 60, May, p. 101629.

Bressanelli, G., Adrodegari, F., Perona, M. and Saccani, N. (2018), "Exploring how usage-focused business models enable circular economy through digital technologies", Sustainability (Switzerland), Vol. 10 No. 3, p. 639.

Brettel, M., Friederichsen, N., Keller, M. and Rosenberg, M. (2014), "How virtualization, decentralization and network building change the manufacturing landscape: an Industry 4.0 Perspective", International Journal of Mechanical, Industrial Science and Engineering, Vol. 8 No. 1, pp. 37-44.

Buckley, P.J. and Strange, R. (2015), "The governance of the global factory: location and control of world economic activity", Academy of Management Perspectives, Academy of Management Briarcliff Manor, NY, Vol. 29 No. 2, pp. 237-249.

Carvalho, N., Chaim, O., Cazarini, E. and Gerolamo, M. (2018), "Manufacturing in the fourth industrial revolution: a positive prospect in sustainable manufacturing", Procedia Manufacturing, Vol. 21, pp. 671-678.

Cassetta, E., Monarca, U., Dileo, I., Di Berardino, C. and Pini, M. (2020), "The relationship between digital technologies and internationalisation. Evidence from Italian SMEs", Industry and Innovation, Taylor \& Francis, Vol. 27 No. 4, pp. 311-339.

Cheng, Y., Matthiesen, R., Farooq, S., Johansen, J., Hu, H. and Ma, L. (2018), "The evolution of investment patterns on advanced manufacturing technology (AMT) in manufacturing operations: a longitudinal analysis", International Journal of Production Economics, Elsevier B.V., Vol. 203, July, pp. 239-253.

Cimini, C., Boffelli, A., Lagorio, A., Kalchschmidt, M. and Pinto, R. (2020), "How do industry 4.0 technologies influence organisational change? An empirical analysis of Italian SMEs", Journal of Manufacturing Technology Management, Emerald Publishing, Vol. 32 No. 3, pp. 695-721.

Cohen, J. (1962), “The statistical power of abnormal-social psychological research: a review”, Journal of Abnormal and Social Psychology, Vol. 65 No. 3, p. 145, doi: 10.1037/h0045186. 
Cohen, J. (2013), Statistical Power Analysis for the Behavioral Sciences, Lawrence Erlbaum Associates Publishers, New York.

Cohen, Y., Naseraldin, H., Chaudhuri, A. and Pilati, F. (2019), "Assembly systems in Industry 4.0 era: a road map to understand Assembly 4.0", The International Journal of Advanced Manufacturing Technology, Vol. 105 No. 9, pp. 4037-4054.

Couper, M.P. (2000), "Web surveys”, Public Opinion Quarterly, Vol. 64 No. 4, pp. 464-494.

Damiani, L., Demartini, M., Guizzi, G., Revetria, R. and Tonelli, F. (2018), "Augmented and virtual reality applications in industrial systems: a qualitative review towards the industry 4.0 era", IFAC-PapersOnLine, Elsevier, Vol. 51 No. 11, pp. 624-630.

Devi, K.S., Paranitharan, K.P. and Agniveesh, A.I. (2021), "Interpretive framework by analysing the enablers for implementation of Industry 4.0: an ISM approach", Total Quality Management and Business Excellence, Vol. 32 Nos 13-14, pp. 1494-1514.

Dilberoglu, U.M., Gharehpapagh, B., Yaman, U. and Dolen, M. (2017), "The role of additive manufacturing in the era of industry 4.0", Procedia Manufacturing, Elsevier, Vol. 11, pp. 545-554.

Dillman, D.A., Smyth, J.D. and Christian, L.M. (2014), Internet, Phone, Mail, and Mixed-Mode Surveys: the Tailored Design Method, John Wiley \& Sons, Hoboken, New Jersey.

EC (2020), Eurostat Database, European Commission; Online Statistical Database, available at: https:/ec. europa.eu/eurostat/statistics-explained/index.php/Industrial_production_statistics\#Overview.

Ellis, P.D. (2010), The Essential Guide to Effect Sizes: Statistical Power, Meta-Analysis, and the Interpretation of Research Results, Cambridge University Press, Cambridge.

Eloranta, V., Ardolino, M. and Saccani, N. (2021), "A complexity management approach to servitization: the role of digital platforms", International Journal of Operations and Production Management, Vol. 41 No. 5, pp. 622-644, doi: 10.1108/IJOPM-08-2020-0582.

Fareri, S., Fantoni, G., Chiarello, F., Coli, E. and Binda, A. (2020), "Estimating Industry 4.0 impact on job profiles and skills using text mining", Computers in Industry, Elsevier B.V., Vol. 118, p. 103222.

Forza, C. (2002), "Survey research in operations management: a process-based perspective", International Journal of Operations and Production Management, Vol. 22 No. 2, pp. 152-194, doi: 10.1108/01443570210414310.

Frank, A.G., Dalenogare, L.S. and Ayala, N.F. (2019), "Industry 4.0 technologies: implementation patterns in manufacturing companies", International Journal of Production Economics, Vol. 210, pp. 15-26.

Galati, F. and Bigliardi, B. (2019), "Industry 4.0: emerging themes and future research avenues using a text mining approach”, Computers in Industry, Elsevier B.V., Vol. 109, pp. 100-113.

García-Magro, C. and Soriano-Pinar, I. (2019), "Design of services in servitized firms: gamification as an adequate tool", Journal of Business and Industrial Marketing, Vol. 35 No. 3, pp. 575-585.

Ghobakhloo, M. (2018), "The future of manufacturing industry: a strategic roadmap toward Industry 4.0", Journal of Manufacturing Technology Management, Vol. 29 No. 6, pp. 910-936.

Gomez, J. and Vargas, P. (2009), "The effect of financial constraints, absorptive capacity and complementarities on the adoption of multiple process technologies", Research Policy, Elsevier, Vol. 38 No. 1, pp. 106-119.

Governo italiano-Ministero dello Sviluppo Economico (2016), Piano Nazionale Industria 4.0, Roma, available at: https://www.mise.gov.it/images/stories/documenti/guida_industria_40.pdf.

Gracel, J. and Lebkowski, P. (2019), "The concept of industry 4.0 related manufacturing technology maturity model (manutech maturity model, MTMM)", Decision Making in Manufacturing and Services, Vol. 12 No. 1, pp. 17-31.

Hanelt, A., Bohnsack, R., Marz, D. and Antunes Marante, C. (2021), "A systematic review of the literature on digital transformation: insights and implications for strategy and organizational change”, Journal of Management Studies, Vol. 58 No. 5, pp. 1159-1197, doi: 10.1111/joms.12639.
The road towards industry 4.0

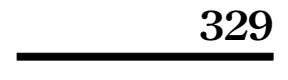


BIJ

30,1

Hecklau, F., Galeitzke, M., Flachs, S. and Kohl, H. (2016), "Holistic approach for human resource management in industry 4.0", Procedia CIRP, Vol. 54, December, pp. 1-6.

Hofmann, E. and Rüsch, M. (2017), "Industry 4.0 and the current status as well as future prospects on logistics", Computers in Industry, Elsevier B.V., Vol. 89, pp. 23-34.

Horváth, D. and Szabó, R.Z. (2019), "Driving forces and barriers of Industry 4.0: do multinational and small and medium-sized companies have equal opportunities?", Technological Forecasting and Social Change, Elsevier, Vol. 146, May, pp. 119-132.

Ivanov, D., Dolgui, A., Sokolov, B., Werner, F. and Ivanova, M. (2016), “A dynamic model and an algorithm for short-term supply chain scheduling in the smart factory industry 4.0", International Journal of Production Research, Taylor \& Francis, Vol. 54 No. 2, pp. 386-402.

Jonsson, P. and Mattsson, S.A. (2006), "A longitudinal study of material planning applications in manufacturing companies", International Journal of Operations and Production Management, Emerald Group Publishing, Vol. 26 No. 9, pp. 971-995.

Kagermann, H., Wahlster, W. and Helbig, J. (2013), Securing the Future of German Manufacturing Industry: Recommendations for Implementing the Strategic Initiative INDUSTRIE 4.0, Forschungsunion Im Stifterverband Für Die Deutsche Wirtschaft e.V, Berlin.

Kamble, S.S., Gunasekaran, A. and Sharma, R. (2018), "Analysis of the driving and dependence power of barriers to adopt industry 4.0 in Indian manufacturing industry", Computers in Industry, Elsevier, Vol. 101, May, pp. 107-119.

Kiel, D., Müller, J.M., Arnold, C. and Voigt, K.-I. (2017), "Sustainable industrial value creation: benefits and challenges of industry 4.0", International Journal of Innovation Management, Vol. 21 No. 8, pp. 1-34, 1740015, doi: 10.1142/S1363919617400151.

Klingenberg, C.O., Borges, M.A.V. and Antunes, J.A.V. Jr (2019), "Industry 4.0 as a data-driven paradigm: a systematic literature review on technologies", Journal of Manufacturing Technology Management, No. 88881, JMTM-09-2018-0325.

Kusiak, A. (2018), "Smart manufacturing", International Journal of Production Research, Taylor \& Francis, Vol. 56 Nos 1-2, pp. 508-517.

Lasi, H., Fettke, P., Kemper, H.-G., Feld, T. and Hoffmann, M. (2014), "Industry 4.0", Business and Information Systems Engineering, Vol. 6 No. 4, pp. 239-242.

Lee, J., Davari, H., Singh, J. and Pandhare, V. (2018), "Industrial Artificial Intelligence for industry 4.0based manufacturing systems”, Manufacturing Letters, Elsevier, Vol. 18, pp. 20-23.

Lefebvre, L., Langley, A., Harvey, J. and Lefebvre, E. (1992), "Exploring the strategy-technology connection in small manufacturing firms", Production and Operations Management, Wiley Online Library, Vol. 1 No. 3, pp. 269-285.

Lu, Y. (2017), "Industry 4.0: a survey on technologies, applications and open research issues", Journal of Industrial Information Integration, Elsevier, Vol. 6, pp. 1-10.

Majumdar, A., Garg, H. and Jain, R. (2021), "Managing the barriers of Industry 4.0 adoption and implementation in textile and clothing industry: interpretive structural model and triple helix framework", Computers in Industry, Elsevier B.V., Vol. 125, p. 103372.

Malik, A.A., Masood, T. and Bilberg, A. (2020), "Virtual reality in manufacturing: immersive and collaborative artificial-reality in design of human-robot workspace", International Journal of Computer Integrated Manufacturing, Taylor \& Francis, Vol. 33 No. 1, pp. 22-37.

Masood, T. and Sonntag, P. (2020), "Industry 4.0: adoption challenges and benefits for SMEs", Computers in Industry, Elsevier B.V., Vol. 121, p. 103261.

Mihardjo, L.W.W., Sasmoko, S., Alamsjah, F. and Elidjen, E. (2019), "Digital leadership role in developing business model innovation and customer experience orientation in industry 4.0", Management Science Letters, Vol. 9 No. 11, pp. 1749-1762. 
Moeuf, A., Pellerin, R., Lamouri, S., Tamayo-Giraldo, S. and Barbaray, R. (2018), "The industrial management of SMEs in the era of Industry 4.0", International Journal of Production Research, Taylor \& Francis, Vol. 56 No. 3, pp. 1118-1136.

Müller, J.M., Kiel, D. and Voigt, K.I. (2018), "What drives the implementation of industry 4.0? The role of opportunities and challenges in the context of sustainability", Sustainability, Vol. 10 No. 1, p. 247.

Nguyen Ngoc, H., Lasa, G. and Iriarte, I. (2021), "Human-centred design in industry 4.0: case study review and opportunities for future research", Journal of Intelligent Manufacturing. doi: 10.1007/ s10845-021-01796-x.

Nimawat, D. and Gidwani, B.D. (2021), "Identification of cause and effect relationships among barriers of Industry 4.0 using decision-making trial and evaluation laboratory method", Benchmarking: An International Journal, Vol. 28 No. 8, pp. 2407-2431, doi: 10.1108/BIJ-08-2020-0429.

Nosalska, K., Piątek, Z.M., Mazurek, G. and Rządca, R. (2020), "Industry 4.0: coherent definition framework with technological and organizational interdependencies", Journal of Manufacturing Technology Management, Vol. 31 No. 5, pp. 837-862, doi: 10.1108/JMTM-08-2018-0238.

Oesterreich, T.D. and Teuteberg, F. (2016), "Understanding the implications of digitisation and automation in the context of Industry 4.0: a triangulation approach and elements of a research agenda for the construction industry", Computers in Industry, Elsevier B.V., Vol. 83, pp. 121-139.

Ojra, A. (2018), "Revisiting Industry 4.0: a new definition", Science and Information Conference, Springer, pp. 1156-1162.

Ortt, R., Stolwijk, C. and Punter, M. (2020), "Implementing Industry 4.0: assessing the current state", Journal of Manufacturing Technology Management, Vol. 31 No. 5, pp. 825-836.

Oztemel, E. and Gursev, S. (2020), "Literature review of Industry 4.0 and related technologies”, Journal of Intelligent Manufacturing, Springer US, Vol. 31 No. 1, pp. 127-182.

Pirola, F., Cimini, C. and Pinto, R. (2019), "Digital readiness assessment of Italian SMEs: a case-study research", Journal of Manufacturing Technology Management, Vol. 31 No. 5, pp. 1045-1083.

Raj, A., Dwivedi, G., Sharma, A., Lopes de Sousa Jabbour, A.B. and Rajak, S. (2020), "Barriers to the adoption of industry 4.0 technologies in the manufacturing sector: an inter-country comparative perspective", International Journal of Production Economics, Elsevier B.V., Vol. 224, August 2019, p. 107546.

Rejikumar, G., Raja Sreedharan, V., Arunprasad, P., Jinil, P. and Sreeraj, K.M. (2019), "Industry 4.0: key findings and analysis from the literature arena”, Benchmarking: An International Journal, Vol. 26 No. 8, pp. 2514-2542.

Ritter, L.A. and Sue, V.M. (2007), "Introduction to using online surveys", New Directions for Evaluation, Vol. 2007 No. 115, pp. 5-14.

Rossini, M., Costa, F., Tortorella, G.L. and Portioli-Staudacher, A. (2019), "The interrelation between Industry 4.0 and lean production: an empirical study on European manufacturers", The International Journal of Advanced Manufacturing Technology, Vol. 102 Nos 9-12, pp. 3963-3976.

Schneider, P. (2018), "Managerial challenges of Industry 4.0: an empirically backed research agenda for a nascent field", Review of Managerial Science, Springer Berlin Heidelberg, Vol. 12 No. 3, pp. 803-848.

Schniederjans, D.G. (2017), "Adoption of 3D-printing technologies in manufacturing: a survey analysis", International Journal of Production Economics, Vol. 183, pp. 287-298.

Schumacher, A., Erol, S. and Sihn, W. (2016), "A maturity model for assessing industry 4.0 readiness and maturity of manufacturing enterprises", Procedia CIRP, Vol. 52, pp. 161-166.

Singleton, R.A. and Straits, B.C. (2012), "Survey interviewing", The SAGE Handbook of Interview Research: The Complexity of the Craft, 2455 Teller Road, Thousand Oaks California 91320 United States, SAGE Publications, pp. 77-98.

Sohal, A.S. and Terziovski, M. (2000), "TQM in Australian manufacturing: factors critical to success", International Journal of Quality and Reliability Management, Vol. 17 No. 2, pp. 158-167. 
BIJ

30,1

332

Srai, J.S. and Lorentz, H. (2019), "Developing design principles for the digitalisation of purchasing and supply management", Journal of Purchasing and Supply Management, Elsevier, Vol. 25 No. 1, pp. 78-98.

Strange, R. and Zucchella, A. (2017), "Industry 4.0, global value chains and international business", Multinational Business Review, Vol. 25 No. 3, pp. 174-184, doi: 10.1108/MBR-05-2017-0028.

Szász, L., Demeter, K., Rácz, B.-G. and Losonci, D. (2021), "Industry 4.0: a review and analysis of contingency and performance effects", Journal of Manufacturing Technology Management, Vol. 32 No. 3, pp. 667-694, doi: 10.1108/JMTM-10-2019-0371.

Tabachnick, B.G., Fidell, L.S. and Ullman, J.B. (2007), Using Multivariate Statistics, Vol. 5, Pearson Boston, MA.

Tiwari, S. (2020), "Supply chain integration and Industry 4.0: a systematic literature review", Benchmarking: An International Journal, Emerald Publishing, Vol. 28 No. 3, pp. 990-1030.

Tortorella, G.L. and Fettermann, D. (2018), "Implementation of Industry 4.0 and lean production in Brazilian manufacturing companies", International Journal of Production Research, Taylor \& Francis, Vol. 56 No. 8, pp. 2975-2987.

Tortorella, G.L., Rossini, M., Costa, F., Portioli Staudacher, A. and Sawhney, R. (2021), "A comparison on Industry 4.0 and Lean Production between manufacturers from emerging and developed economies", Total Quality Management and Business Excellence, Vol. 32 Nos 11-12, pp. 1249-1270.

Turner, C.J., Hutabarat, W., Oyekan, J. and Tiwari, A. (2016), "Discrete event simulation and virtual reality use in industry: new opportunities and future trends", IEEE Transactions on HumanMachine Systems, IEEE, Vol. 46 No. 6, pp. 882-894.

Ustundag, A. and Cevikcan, E. (2018), "Industry 4.0: managing the digital transformation", Springer Series in Advanced Manufacturing, Springer International Publishing, Cham. doi: 10.1007/978-3319-57870-5.

Veile, J.W., Kiel, D., Müller, J.M. and Voigt, K.-I. (2019), "Lessons learned from Industry 4.0 implementation in the German manufacturing industry", Journal of Manufacturing Technology Management, Vol. 31 No. 5, pp. 977-997.

Veza, I., Mladineo, M. and Gjeldum, N. (2015), "Managing innovative production network of smart factories", IFAC-PapersOnLine, Elsevier, Vol. 48 No. 3, pp. 555-560.

Wagire, A.A., Rathore, A.P.S. and Jain, R. (2019), "Analysis and synthesis of Industry 4.0 research landscape”, Journal of Manufacturing Technology Management, Vol. 31 No. 1, pp. 31-51.

Wagner, S.M. and Kemmerling, R. (2010), "Handling nonresponse IN logistics research", Journal of Business Logistics, Vol. 31 No. 2, pp. 357-381.

$\mathrm{Xu}$, L.D. and Duan, L. (2019), "Big data for cyber physical systems in industry 4.0: a survey", Enterprise Information Systems, Vol. 13 No. 2, pp. 148-169.

Zheng, T., Ardolino, M., Bacchetti, A., Perona, M. and Zanardini, M. (2019), "The impacts of Industry 4.0: a descriptive survey in the Italian manufacturing sector", Journal of Manufacturing Technology Management, Emerald Group Publishing, Vol. 31 No. 5, pp. 1085-1115.

Zheng, T., Ardolino, M., Bacchetti, A. and Perona, M. (2021), "The applications of Industry 4.0 technologies in manufacturing context: a systematic literature review", International Journal of Production Research, Vol. 59 No. 6, pp. 1922-1954.

\section{Corresponding author}

Marco Ardolino can be contacted at: marco.ardolino@unibs.it

For instructions on how to order reprints of this article, please visit our website:

www.emeraldgrouppublishing.com/licensing/reprints.htm

Or contact us for further details: permissions@emeraldinsight.com 